\title{
Eine Revolution der Medizingeschichte
}

Die Möglichkeit, durch eine Hepatitis C-Infektion eine Leberzirrhose oder Leberkrebs zu entwickeln, ist existent - auch wenn es von der Virusinfektion bis zum Leberschaden einige Zeit dauern kann. Daher lautet der Apell der Experten: Früh diagnostizieren! Dem steht jedoch die lange Symptomlosigkeit der Erkrankung und das Unwissen der breiten Öffentlichkeit entgegen. Die neuen Interferon-freien Therapien stellen jedenfalls eine große Hoffnung für Betroffene in jedem Stadium der Krankheit dar - ohne Nebenwirkungen. Seit 1. Dezember 2015 steht die Informationsplattform www.hepatitisc-info.at im Internet zur Verfügung.

Schätzungen zufolge sind österreichweit 40.000 Menschen an chronischer Hepatitis C erkrankt, die Dunkelziffer ist nach wie vor hoch, da die Symptome erst im späteren Verlauf der Erkrankung auftreten. Vor allem die weltweite Mobilität führt dazu, dass eine Infektion jeden treffen kann. Denn während Blut und Blutprodukte aufgrund der hohen Qualitätsstandards in unseren Breiten heute als Infektionsquelle praktisch auszuschließen sind, ist dies in anderen Teilen der Welt und in vielen beliebten Reisezielen noch nicht der Fall.

Neuinfektionen finden zwar heute zu einem Großteil durch i.v.-Drogenkonsum mit geteilten Spritzennadeln statt, derzeit sei aber beispielsweise im Wilhelminenspital die Infektionsquelle bei einem beträchtlichen Teil der Patienten nicht identifizierbar, stellte Prof. Michael Gschwantler, Vorstand der 4. Med. Abt. im Wilhelminenspital Wien, fest. In der Bevölkerung ist die Assoziation zwischen Hepatitis C-Erkrankung und Drogenkonsum aber überproportial verankert.

Immerhin 45\% der Befragten sind der Meinung, dass man sich gegen Hepatitis C mit einer Impfung schützen könne. Daher, so Dr. Thomas Czypionka, Leiter des Forschungsbereichs Gesundheitsökonomie und Gesundheitspolitik im Institut für Höhere
Hausarzt bis zum Pflegepersonal." Die Krankheit, so Gschwantler und Czypionka, müsse aus der Tabuzone geführt werden.

\section{Empfindliche Österreicher}

Hepatitis C-Erkrankte fühlen sich häufig stigmatisiert, wobei diese Tabuisierung auf europäischer Ebene weiter verbreitet ist als in Österreich. Zu diesem Ergebnis kommen aktuelle internationale (HCV Quest) und österreichische - vom Pharmaunternehmen AbbVie beauftragte und von medupha Health Care Research durchgeführte - Umfragen zum Hepatitis C-Wissensstand der Bevölkerung, die Ende vergangenen Jahres in Wien präsentiert wurden. So gaben bei HCV Quest 32\% an, dass sie ihrer Familie gegenüber nichts von der Erkrankung erzählt haben, während $67,5 \%$ mit engen Familienangehörigen und 35,6\% mit Freunden darüber gesprochen haben. $88 \%$ in der österreichischen Befragung haben mit engen Familienangehörigen über ihre Erkrankung gesprochen, $71 \%$ haben Freunde und Freunde der Familie informiert. Während auf internationaler Ebene $64 \%$ angaben, die Erkrankung habe Auswirkungen auf die Arbeit, waren dies in der österreichischen Befragung nur $27 \%$.

Allerdings fühlen sich die Österreicher stärker von der Erkrankung betroffen und sind offenbar sensibler: Die Auswirkungen der Krankheit auf ihre körperliche Befindlichkeit bewerteten in HCV Quest $45 \%$ als deutlich negativ, in Österreich empfanden dies
$70 \%$. Ähnlich verhält es sich auf der emotionalen Ebene: Weltweit gaben $37 \%$ Auswirkungen ihrer Hepatitis C-Erkrankung auf die emotionale Verfassung an, in Österreich sind es $64 \%$.

Als "Revolution der Medizingeschichte, die nur wenige Parallelen hat", bezeichnete Gschwantler die neuen Therapien:„,Dank der neuen Interferon-freien Therapie sind wir nun erstmals in der Lage, das Hepatitis C-Virus bei praktisch allen Betroffenen zu beseitigen. In der Folge kann sich die Erkrankung nicht nur nicht mehr ausbreiten, auch kann sich beispielsweise ein bereits entstandener Leberschaden langsam wieder zurückbilden." Die Heilungschancen mit den neuen Interferon-freien, direkt an der Virus-DNA wirkenden Wirkstoffen betragen je nach Virus-Genotyp knapp $100 \%$ bei Genoty 1 bzw. beim für diese Therapie ungünstigeren - bei uns auch weniger verbreiteten - Genotyp 3 und bei Vorliegen einer weit fortgeschrittenen Leberzirrhose $90 \%$.

Tipps für das Leben nach der Heilung, sowie Informationen über Ansteckungsmöglichkeiten und Symptome finden Interessierte und Betroffene auf der Internetseite von AbbVie www.hepatitisc-info.at.

Wien klin Mag 2016 · 19:30 DOI 10.1007/s00740-016-0089-2

Online publiziert: 25. Januar 2016 (c) Springer-Verlag Wien 2016 